\title{
Proximity and Self-Correlation of Municipalities in the Republic of Benin
}

\author{
ACACHA Hortensia \\ ENEAM UAC Assistant Master Cams \\ E-mail: horcacha@yahoo.fr
}

Received: December 8, 2018 Accepted: March 7, 2019 Published: June 17, 2019

doi:10.5296/bms.v10i1.14935 URL: https://doi.org/10.5296/bms.v10i1.14935

\begin{abstract}
The purpose of this study is to provide a detailed description of the spatial distribution of tax revenues, non-tax revenues and capital expenditures of the Communes in the Republic of Benin, to analyze the spatial interactions between the Commons and to deduce from them Communes with a strong neighborhood of spatial interaction.

The methodological approach consisted in using a database, in the construction of an adjacency matrix that made it possible to conceptualize and take into account the neighborhood links. The degree of spatial dependence is captured from the global and local spatial indices of Moran.

The main findings of the study indicate that the tax revenues and capital expenditures of the Commons are characterized by a random distribution. On the other hand, non-tax revenue is spatially self-correlated. However, local spatial analyzes reveal that some municipalities seem to be concentrating above average levels of tax revenue and investment spending in their neighborhoods. In addition, the analyzes revealed that the influence of the urbanization rate on the level of tax revenue, non-tax revenue and investment expenditure is barely perceptible. It is therefore necessary to review a better orientation of local development policies.
\end{abstract}

Keywords: R11 R12 R28 R(\& 


\section{Introduction}

One of the decisions of the February 1990 conference of the forces of the Nation is the adoption of Decentralization as a system of local governance. But after more than two decade of experimentation with decentralization, it is clear that local communities are struggling to play the role of impulse and development at the base they deserve. Indeed, the incidence of income poverty stood at 40.2\% in 2015 against 36.2\% in 2011 and 33.3\% in 2007, which represents a worsening of 4 points between 2011 and 2015 against a decline by 2.9 points compared to 2007 (EMICOV,2015). The same report reveals the existence of large regional disparities in monetary poverty in 2015. Are municipalities with similar economic development indicators in the same neighborhood? Similarly, are municipalities with a low level of economic development usually rural?

\subsection{Objectives of the Study}

The main purpose of this study is to contribute to a better formulation of local development policies for more efficiency and effectiveness. Specifically, it is about; : Analyzing the Spatial Disparity of Tax, Non-Tax and Capital Gains in the municipalities and analyzing Spatial Interactions Between Municipalities to deduce the municipalities with strong neighborhood of spatial interaction.

\subsection{The Hypotheses}

The following hypotheses can be tested namely:

H1: the proximity of the municipalities influences their investment spending and their tax and non-tax revenues;

\subsection{Clarifiacation Of Concepts}

\subsubsection{Growth Pole}

According to the theory of growth poles, stated by François Perroux (1950), "growth does not appear everywhere at once; it manifests itself in certain points, or poles of growth, with varying intensities; it is spread by various channels with terminal effects variables for the whole economy ". no italic

\subsubsection{Tax Revenues}

Tax revenue refers to revenue from income and profit taxes, social security contributions, taxes on goods and services, wage levies, wealth taxes, and transfer taxes. than other taxes.

\subsubsection{Non-Tax Revenue}

Non-tax revenue refers to the municipalities' own revenue from the products of services, domain and miscellaneous sales. 


\subsubsection{Clean Recipes}

They include tax revenue (recorded in account 71, excluding the elements of 713 "Tax refund and refund"which are "shared revenue") and non-tax revenue (recorded in account 70 of the budget nomenclature of communes in the Republic of Benin).

\subsubsection{Shared Recipes}

Shared revenue is the revenue from taxes that municipalities share with the state and sometimes other governments. They are recorded in account 713 of the budgetary nomenclature of the Communes "Reversal and restitution on taxes ".

\subsubsection{Investment Expenditure}

Capital expenditures consist mainly of operations that result in a change in the consistency or value of the territorial community's assets: purchases of durable equipment, construction or development of buildings, infrastructure works and acquisition of securities.

\subsubsection{Investment}

Investment is defined as "an immediate advance of monetary resources intended to induce reductions in monetary charges in the future.”According to Gérard (1996). Thus understood, such a notion seems too general in relation to the study by Patrick Villieu (2000) who defines investment in the economic sense as "the acquisition of tangible or intangible goods of production".

\subsubsection{Spatial Autocorrelation}

- In empirical work, the economist is often confronted with the use of localized data, that is, the processing of observations of a variable measured at different locations distributed in space. It is often accepted that these spatial data observed in cross section are independent whereas this assumption is rarely justified and should be systematically tested. Thus, as early as 1914, Student suspected the presence of a relationship between different localized observations.

- Historically, it is to Cliff and Ord that, after a series of articles in the late sixties and early seventies, a book summarizing the state of knowledge in statistics and in spatial econometrics (1973). The late seventies and eighties are marked by the refinement of the original framework of analysis of Cliff and Ord, more particularly by the development of the theory of estimation and tests (Ord, 1975; Paelinck and Klassen, 1979 ; Anselin, 1980). A number of books report on these developments Cliff and Ord (1981), Anselin (1988a), Cressie (1993), Jayet (1993), Anselin and Florax (1995a).

- Until recently, techniques for specifying, estimating and testing the presence of spatial autocorrelation in econometric models were mainly published in specialized journals and applied to problems of regional, spatial or urban economics. Thus Can (1992), Can and Megboluge (1997), Pace and Gilley (1997) addressed the treatment of spatial 
autocorrelation in hedonic models of real estate prices, while Anselin, Varga and Acs (1997) and Varga (1998) studied spatial externalities of information due to university research and R \& D. However, spatial econometric methods are now applied to other topics such as demand analysis (Case, 1991), the international economy (Aten, 1997), public economics (Case et al., 1993; Brueckner, 1998), the rural economy (Benirschka and Binkley, 1996), or the phenomena of growth and convergence (Moréno and Treban, 1997); Rey and Montouri, 1999, Fingleton 1999; Baumont et al., 2001). These methods are indeed potentially applicable to all empirical studies requiring the use of spatial data.

- According to Anselin and Bera (1998) and Anselin (2000), two main reasons can be attributed to the renewed attention paid to the consideration of spatial autocorrelation in empirical studies in economics. The first is the development of new theoretical currents, such as the geographical economy and its ramifications in industrial economics, international economics, theories of growth or labor economics, which have generalized the taking into account of spatial interactions and externalities. The analysis of the economic decisions of the agents. Spatial autocorrelation is the lack of independence between geographical observations. So, he is found very often that spatialized variables are subject to spatial dependencies (or spatial interactions), which are all the stronger as the locations are closer: "everything is related to everything else, but near things are more related than distant things "(Tobler, 1970).

Anselin and Bera (1998) have offers a intuitive definition of autocorrelation space: "Spatial autocorrelation can be loosely defined as the coincidence of similarity with locational similarity”. On the other hand, negative spatial autocorrelation means that each location tends to be surrounded by neighboring locations for which the random variable takes very different values. Finally, the absence of spatial autocorrelation indicates that the spatial distribution of the values of the variable is random.

\section{Method}

\subsection{The Data of the Study}

The data used in this study come primarily from two sources. Budget data are from 2013 and provided by the National Commission of Local Finance (CONAFIL). Budget data from CONAFIL refer to the 77 municipalities in Benin.

Information on demography comes from the village notebooks and city districts prepared by the National Institute of Statistics and Economic Analysis (INSAE) as part of the popularization of the results of the fourth General Census of Population and Housing (RGPH4). The intercommunal connectivity matrix was built from mapping and existing monographs on communes.

All municipalities were selected for the analyzes. The population concerned is the total population of Benin according to the RGPH4. The variables we consider in our analysis are tax and non-tax revenues, and capital expenditures. 


\subsection{Descriptive Statistics}

They will be used to highlight the disparities tax revenues, the non-tax revenue and capital expenditures of Commons. It will also be necessary to show the heterogeneity linked to the size and demography of Benin's municipalities. This first analysis will provide a better understanding of the analysis of interactions related to territorial organization.

The characteristics of central tendency (arithmetic mean, median and mode) and the characteristics of dispersion (standard deviation, coefficient of variation, Gini coefficient and quantiles) will be used.

\subsection{Exploratory Analysis of the Data}

For the demonstration of a spatial dependence reflecting social interactions, the literature uses exploratory analysis of data. (Crouxet Wasmer, 2000). Exploratory analysis of spatial data is a set of techniques used to describe and visualize spatial distributions, to identify atypical locations, extreme observations and spatial groupings, to detect patterns of spatial associations (Anselin, 1998). This technique focuses on distinguishing the characteristics of spatial data. (Anselin, 1989).

\subsection{Establishment of Contiguity Relations}

The measurement of the spatial correlation between agents or geographical areas begins with the definition of neighborhood relations between the agents or the geographical zones that are, in the context of this study, the 77 municipalities of Benin.

Thus, if we observe $\mathrm{N}$ regions, there are $\mathrm{N}(\mathrm{N}-1)$ / 2 different pairs of regions. It is therefore not possible to identify correlation relations between these $\mathrm{N}$ regions without making assumptions about the structure of this spatial correlation. For the 77 municipalities, this amounts to defining a square matrix e of size $77 * 77$, whose diagonal elements are null (a commune can not be its own neighbor). The value of the non-diagonal elements then depends on the type of matrix retained. Many neighborhood matrices have been proposed in the literature. The main ones are the following:

-are the adjacency matrices that associate with each immediate neighbor to 1 (and 0 otherwise). Generally, the notion of neighborhood refers to the existence of a common border or not. Thus, one municipaliy will be considered as neighbor of another if both have a common border;

-the matrices taking into account the distance between the geographical areas ( 1 if $\mathrm{d}<\mathrm{d} 0,1$ / $\mathrm{d}^{2}$, e- ${ }^{2 \mathrm{~d}}$...). Several indicators can be used according to the definition of distance: distance as the crow flies, distance by road or generalization to transport times or accessibility indices. Various specifications are also available, the most used ones being the negative exponential function or a function of the inverse of the distance. It is assumed in this case that the intensity of the interaction between two regions $i$ and $j$ depends on the distance between the centroids of these regions.; 
-the matrices of the nearest neighbors.

For ease of interpretation, these neighborhood matrices are most often standardized per line, ie the sum of the elements per line is 1 . For an adjacency matrix, if a neighboring region ak, each non zero term of the $\mathrm{k}$-th line will be equal to 1 / $\mathrm{k}$. The term Wy is simply interpreted as the neighborhood mean for the variable y.

In the context of the present study, contiguity relations were constructed with the statistical software R and for this purpose, the main input is the polygonal spatial object made on the 77 Communes of Benin and including the geographic coordinates multiple points pertaining to these Commons. All geographic objects used in this study were obtained in the laboratory of the Department of Geography of the University of Abomey.

\subsection{Global Space Autocorrelation Test}

For the measurement of global spatial autocorrelation, two statistics are used: Moran I and Geary C.

\subsubsection{Statistic I of Moran}

Let $x i$ be the value measured for the common i of the variable $\mathrm{x}$ whose spatial distribution we want to study. The Moran statistic I, which is only the correlation coefficient applied to spatial data, is calculated using the following formula:

$$
I_{\text {Moran }}=\frac{\mathrm{n}}{\sum_{i=1}^{n} \sum_{j=1}^{n} \text { wij }} * \frac{\sum_{i=1}^{n} \sum_{j=1}^{n} w i j\left(x_{i}-\bar{x}\right)\left(x_{j}-\bar{x}\right)}{\sum_{i=1}^{n}(\mathrm{xi}-\overline{\mathrm{x}})^{2}}
$$

where $i, j=$ spatial unit; $n=$ number of spatial units; $x i$ is the value of the variable in unit $i$ and $w i j$ are the elements of the spatial interaction matrix, defined in the form of contiguity, distances or common boundaries.

The Moran index thus measures the deviations from the average of its neighbors.

Like the correlation coefficient, It is between -1 and 1 . The autocorrelation is positive (negative) if I is strictly positive (negative). The absence of autocorrelation corresponds to a zero I index.

\subsubsection{Statistics C of Geary}

Geary's statistics measure the deviations of each place from each of the neighbors. She is more sensitive to local variations. His formula is:

$$
C_{G E A R Y}=\frac{(n-1) \sum_{i=1}^{n} \sum_{j=1}^{n} w i j\left(x_{i}-x_{j}\right)^{2}}{2\left(\sum_{i=1}^{n} \sum_{j=1}^{n} w_{i j}\right) \sum_{i=1}^{n}(x i-\bar{x})^{2}}
$$


wherei, $\mathrm{j}$ = spatial unit; $\mathrm{n}=$ number of spatial units; $\mathrm{xi}, \mathrm{xj}$ are the values of the variable in unit $\mathrm{i}$ respectively $\mathrm{j}$ and wij are the elements of the matrix of spatial interactions, defined as contiguity, distances or common boundaries. As with the Moran index, the Geary index can be tested by transformation into scores.

The Geary index means a positive autocorrelation if it is less than 1.

The significance test is done in the same logic as that of the Moran index. In the literature, Moran's index is often preferred to Geary's because of greater overall stability (Upton and Fingleton, 1985).

Statistics I and C provide very important information on whether or not communities are ordered or not in space; This may suggest inter- communal or non-shared spatial interactions. However, they do not make it possible to know the spatial structure of the communes or if there are atypical localizations.

\subsubsection{Local Spatial Autocorrelation}

The analysis of spatial autocorrelation requires that, after the evaluation of global autocorrelation, the local spatial autocorrelation be evaluated. In fact, the local autocorrelation tests (LISA) allow us to take a more precise look at sub-regional variations, regardless of the overall spatial structure. The local spatial autocorrelation thus makes it possible to assess the intensity and the significance of the local dependence between the value of a variable in a spatial unit (common for example) and the values of this same variable in the surrounding spatial units (more or less). less close). The local statistics thus make it possible to deepen the knowledge of the process which gives rise to a global spatial association. They measure the concentration around each of the geographical locations considered (communes). They thus make it possible to measure the propensity of an area to group high or low values of y or, conversely, very different values.

When the local spatial autocorrelation is positive, the considered commune has a neighborhood which concentrates a "wealth"higher than the average of the total sample.

If, on the contrary, it is negative, the commune in question has a neighborhood composed of poor people.

The formula for the local Moran index is as follows:

$$
I_{i}=\frac{(n-1)\left(x_{i}-\bar{x}\right)}{\sum_{j=1}^{n}(\mathrm{x} j-\overline{\mathrm{x}}) 2} \sum_{j=1}^{n} w i j\left(x_{j}-\bar{x}\right)
$$

\section{Moran Diagram}

The Moran diagram highlights forms of autocorrelation spatiale and examine local instability. In this diagram the abscissa in FIG Variable is unknown centered value $\mathrm{z}$ and the ordinate its 
standardized spatial shift Wz where W is the matrix of connectivity standardized.

Moran diagram divides the plane into four quadrants which correspond to four types of existing spatial association between a joint and its neighbors.

Quadrants HH (a joint associated with a high value surrounded by different municipalities high value) and BB (a common associated with low value municipalities surrounded low value) represent a positive spatial autocorrelation.

On the contrary, $\mathrm{BH}$ and $\mathrm{HB}$ quadrants represent an autocorrelation spatial negative. HB configurations correspond to high values in cities that are surrounded by towns with low values. The $\mathrm{BH}$ configurations correspond to low values in common and which are surrounded by high values in common. The Moran scatterplot can detect atypical localizations that is to say municipalities which deflect the overall scheme of spatial association.

Moran diagram also allows to schematize the overall spatial autocorrelation in so far I Wz slope of the regression line $\mathrm{z}$.

Although the index of global spatial autocorrelation emerged strong enough significance, this may be the fact other variables that are highly correlated to those we study. Thus the conclusion would be induced bias. The implementation of an econometric validation procedure is necessary (Anselin, 1988). The model econometric confirm the robustness of the results emerged from the global autocorrelation indices.

spatial econometric model

The econometric model spatial help to validate the robustness of the exploratory results spatiaux effects the amounts of revenue and capital expenditure.

Thus, a spatial model is used to check if the observation $y i$ is explained by the values taken by the variables $X$ in the area $i$ and the variable $Z$ in the neighboring regions.

Indeed, if the revenue own or joint capital expenditures are related their socio-economic context and even politics, as recognized Guengant, the contextual framework related to space can not be overlooked in explaining those variables budget.

It is possible that town will not spend or can mobilize revenue is demographically less, and at the same time its inhabitants actually migrated to a nearby town serviced more.

\section{Presentation and Analysis of Results}

The presentation of the results will be as follows: Initially, there will be the presentation of results demonstrating the disparity in common in terms of fiscal variables under review namely capital expenditure, tax revenues and non-tax revenues. Then follow the analysis of global and local spatial autocorrelation, ending with the presentation of the econometric results. 


\subsection{Exploratory Data Analysis}

\section{Differences in space of tax revenue, income tax and non-investment expenditures}

Space release of tax revenue

Table 1. Spatial Dispersion tax revenues

\begin{tabular}{|l|l|}
\hline Minimum & 1475 \\
\hline $1^{\text {st }}$ Quartile & 31400 \\
\hline Median & 60870 \\
\hline Average & 191800 \\
\hline $3{ }^{\text {rd }}$ Quartile & 100900 \\
\hline Maximum & 7 \\
\hline Variance & 7239000 \\
\hline Standard Deviation & 850701.6 \\
\hline Coefficient of variation & 4.44 \\
\hline
\end{tabular}

Source: Author's Works, 2016

It is noted a dispersion of my both revenue fiscales. the standard deviation (850 701.6) confirmed by that the coefficient of variation $(4,44)$ explain dispersion common in terms of revenue mobilized.

This dispersion is characterized in detail by the following statistics: minimum (1 475 000), maximum (7 439 000), that artiles (Q1, Me, Q3). $50 \%$ of the total workforce of Commons mobilizes each more than 60.87 million (60 870 000) CFA francs for an average annual revenue of one hundred and four: Twenty-one million eight hundred thousand (191800000) FCFA (median) of tax revenue. Similarly, it should be noted that for the average level of tax revenues, $75 \%$ of municipalities both posted tax revenue of an amount less than or equal to one hundred million nine hundred thousand (100 900 000) FCFA.

The value of the Gini index (0.7613358) confirms the unequal distribution of revenue in the Municipalities of the Republic of Benin.

Pace release of non-tax revenue 
Table 2. Dispersion of spatial non-tax revenues

\begin{tabular}{|l|l|}
\hline Minimum & 120 \\
\hline $1{ }^{\text {st }}$ Quartile & 22030 \\
\hline Median & 41,540 \\
\hline Average & 115600 \\
\hline $3{ }^{\text {rd }}$ Quartile & 86730 \\
\hline Maximum & 1 \\
\hline Variance & 58192000 \\
\hline Standard Deviation & 241246.6 \\
\hline Coefficient of variation & 2.09 \\
\hline
\end{tabular}

Source: Author's Works, 2016

It is noted dispersion of the amount of non-tax revenues. The importance of the standard deviation (241 246.6) confirmed that the coefficient of variation (2.09) expresses the dispersion common in terms of revenue non tax mobilized.

This dispersion is characterized in detail by the following statistics: minimum (120 000), and maximum (1 762 000), and quartiles (Q1, Me, Q3). 50\% of the total workforce of municipalities each mobilizes more than 41.54 million (41 540 000) CFA francs for an average level of income not annual tax hundred fifteen million six one hundred thousand (115 600 000) CFA francs (median) revenue not tax. Similarly, it should be noted that for this average level of revenue, $75 \%$ of Towns displayed each recipe not tax an amount less than or equal to 86.73 million (86 730 000) CFA francs.

The value of the Gini index (0.6656499) confirms the unequal distribution of income not tax at the Municipalities of the Republic of Benin.

Graph 2. Lorenz curve of the distribution of non-tax revenue

\subsection{Space Release of Investment Expenditures Of Commons}

Capital expenditures are an indicator of economic development. Indeed, the supply of resources and the demand for public goods tend to increase as an economy develops. (Abecassis 1994). First, u n given volume of capital expenditure reflects the existence and 
importance of resources mobilized, which in turn result from the economic dynamism of the territory. On the other hand, the more the economy is developed, more infrastructure spending are needed.

Table 3. Spatial spread of investment spending

\begin{tabular}{|l|l|}
\hline Minimum & 128400 \\
\hline $1{ }^{\text {st }}$ Quartile & 243800 \\
\hline Median & 319000 \\
\hline Average & 374200 \\
\hline $3{ }^{\text {rd }}$ Quartile & 411000 \\
\hline Maximum & $3 \quad 300,000$ \\
\hline Variance & 126529358166 \\
\hline Standard Deviation & 355709.7 \\
\hline Coefficient of variation & 0.95 \\
\hline
\end{tabular}

Source: Author's Works, 2016

It is noted a low dispersion of the amount of investment of Commons in 2013. The value of the standard deviation (355 709.7) and that of the coefficient of variability (0.95) conferment this low dispersion of Commons in terms of capital expenditure.

This low dispersion is characterized in detail by the following statistics: minimum (128 400), maximum (3 300 000), and quartiles (Q1, Me, Q3). It is noted that 50\% of the total number of municipalities make investments in the amount of up to three hundred and nineteen million (319 000 000) CFA francs for an average level of expenditures annual investment of three hundred and sixty four million two hundred thousand (374 200 000) CFA (median) of investments. Similarly, it is remark than this average level of capital expenditure, $75 \%$ of municipalities appear each investment of a lower or equal amount to four hundred and eleven million (411 000 000) CFA francs.

This low dispersion of capital expenditure can be explained by the balance of transfers from the state towards the municipalities through the resources of Commons Development Fund (FADEC) which varies little from a Town other. The central government transfers to local authorities allow a significant increase in average of resources ommunes. 
This situation is traced in the following statistics:

Table 4. Spatial spread of investment resources from the FADEC

\begin{tabular}{|l|l|}
\hline Minimum & 227400 \\
\hline $1{ }^{\text {st }}$ Quartile & 284800 \\
\hline Median & 325900 \\
\hline Average & 339900 \\
\hline $3{ }^{\text {rd }}$ Quartile & 366500 \\
\hline Maximum & 926700 \\
\hline Variance & 8332794643 \\
\hline Standard Deviation & 91284.14 \\
\hline Coefficient of variation & 0.27 \\
\hline
\end{tabular}

Source: Author's Works, 2016

For a medium level of FADEC resource transfer of three hundred thirty-nine million nine hundred thousand (339 900 000) CFA francs, it is noted that $75 \%$ of the communes show a lower transfer amount or equal to three hundred sixty-six million five hundred thousand (366 500 000) FCFA.

The FADEC Resources deducting capital expenditures, provides investment spending outside FADEC that best reflect the investment efforts of Commons. The spatial dispersion of said expenses is as follows:

\subsection{Space Release of Investment Expenditures Out Fadec Common}

Table 5. Spatial spread of investment spending outside FADEC Commons

\begin{tabular}{|l|l|}
\hline Minimum & 210600 \\
\hline $1{ }^{\text {st }}$ Quartile & 53,190 \\
\hline Median & 90 \\
\hline
\end{tabular}




\begin{tabular}{|l|l|}
\hline Average & 34,310 \\
\hline $3{ }^{\text {rd }}$ Quartile & 66350 \\
\hline Maximum & $2 \quad 373000$ \\
\hline Variance & 79427648409 \\
\hline Standard Deviation & 281829.1 \\
\hline Coefficient of variation & 8.21 \\
\hline
\end{tabular}

Source: Author's Works, 2016

The previous table shows that $25 \%$ of municipalities recorded a level of investment FADEC out negative. In other words, approximately nineteen (19) municipalities make investments for an amount lower than the FADEC transfers allocated to investments. The average investment is FADEC out of thirty-four million three 100-10000 (34 310 000) CFA francs. Investment FADEC out the lowest recorded level of Commons in 2013 is -210 600000 FCFA while the highest degree is 2373000000 FCFA.

It is clear from the above that the dispersion of values is more pronounced in investment spending outside FADEC.

\subsection{Space Release the Demographics of Commons}

The size of the population that may impact levels of revenue and capital expenditure in the Commons, it is important to focus on the dispersion of population sizes of Commons as part of the analysis of spatial autocorrelation of their economic development.

Table 6. Spatial Dispersion Population

\begin{tabular}{|l|l|}
\hline Minimum & $\mathbf{1 6 8 8 0}$ \\
\hline $1{ }^{\text {st }}$ Quartile & $\mathbf{7 8 9 9 0}$ \\
\hline Median & 107200 \\
\hline Average & 128000 \\
\hline $3{ }^{\text {rd }}$ Quartile & 131300 \\
\hline Maximum & $\mathbf{6 7 9 0 0 0}$ \\
\hline
\end{tabular}




\begin{tabular}{|l|l|}
\hline Variance & $\mathbf{1 0 5 0 9 7 3 1 1 5 2}$ \\
\hline Standard Deviation & $\mathbf{1 0 2 5 1 7}$ \\
\hline Coefficient of variation & 0.80 \\
\hline
\end{tabular}

Source: Author's Works, 2016

\subsection{Analysis of spatial interactions municipalities}

Analysis adjacency matrix

The results of the construction of the matrix adjacency by the R software are as follows:

Table 7 a. Results of the adjacency matrix

\begin{tabular}{|l|l|}
\hline Number of regions & 77 \\
\hline Number of nonzero links & $\mathbf{3 5 6}$ \\
\hline Percentage of non-zero weight & $\mathbf{6 . 0 0 4 3 8 5}$ \\
\hline Averagenumber of links & $\mathbf{4 . 6 2 3 3 7 7}$ \\
\hline 3 Town shaving few neighbors & $\mathbf{1 ; 7}$ \\
\hline $\begin{array}{l}\text { The four municipalities having } \\
\text { more neighbors }\end{array}$ & $\mathbf{2 9 ; 3 4 ; 3 9 ; 5 3}$ \\
\hline
\end{tabular}

Source: Author's Works, 2016.

Table 7b. Results of the adjacency matrix (Distribution of the number of links)

\begin{tabular}{|l|l|l|l|l|l|l|l|l|l|}
\hline Number of links & $\mathbf{1}$ & $\mathbf{2}$ & $\mathbf{3}$ & $\mathbf{4}$ & $\mathbf{5}$ & $\mathbf{6}$ & $\mathbf{7}$ & $\mathbf{8}$ & $\mathbf{9}$ \\
\hline $\begin{array}{l}\text { Number of } \\
\text { Commons }\end{array}$ & $\mathbf{3}$ & $\mathbf{6}$ & $\mathbf{1 0}$ & $\mathbf{1 8}$ & $\mathbf{1 7}$ & $\mathbf{1 6}$ & $\mathbf{2}$ & $\mathbf{1}$ & $\mathbf{4}$ \\
\hline
\end{tabular}

Source: Author's Works, 2016

Theseresultsindicatethat:

- There are 356 links between the 77 municipalities that make up the Republic of Benin.

- These links 356 represent around 6\% of the possible crosses between Towns (5929 possible 
crosses). - Each Commune has averaged 4.62 Other towns. The neighbor relationship is high for 4 municipalities that own 9 Other towns. These are the municipalities Djidja, Zogbodomey, Lalo and ZE.

- The neighbor relationship is very low for three municipalities that have only one neighboring commune. This is of Commons Matéri, Karimama and Tanguiéta.The manual verification of this last result shows that these municipalities have actually more of a neighboring commune. The differences with the results of the software can therefore be explained by the incompleteness of geographical surveys at the Matéri of Commons and Karimama Tanguiéta and contained in the operated geographic objects.

3.6 Test Autocorrelation Global Moran Tax Revenue Revenue no Fiscal and Investment Expenditures (Type Contiguity)

Table 8. Moran test on different variables

\begin{tabular}{|c|c|c|c|c|c|}
\hline variables & I & E (I) & $\begin{array}{l}\text { Std. Err. } \\
\text { (I) }\end{array}$ & p-value & Obs. \\
\hline Tax revenues & 0.060077297 & -0.013157895 & 1.0179 & 0.3087 & 77 \\
\hline $\begin{array}{l}\text { Non-tax } \\
\text { revenues }\end{array}$ & 0.264621574 & -0.013157895 & 3.8609 & 0.0001129 & 77 \\
\hline investments & 0.040948550 & -0.013157895 & 0.75204 & 0452 & 77 \\
\hline $\begin{array}{l}\text { Investment sex } \\
\text { cluding FADEC }\end{array}$ & 0.039526665 & -0.013157895 & 0.73228 & 0464 & 77 \\
\hline
\end{tabular}

Source: Author's Works, 2016

For tax revenue, investments and investments outside FADEC, the p-value (critical probability) on the null hypothesis of spatial autocorrelation is greater than e at threshold $5 \%$. It follows that the spatial autocorrelation is significant for either tax revenues or for capital expenditures or for investments adjusted for FADEC transfers. The distribution of values of these variables is random. Compared to these variables, i s is thus no interaction between the municipalities. The consideration of demographics (variable ratio) leads to the same conclusion from a random distribution.

This is illustrated by the graphic below. 


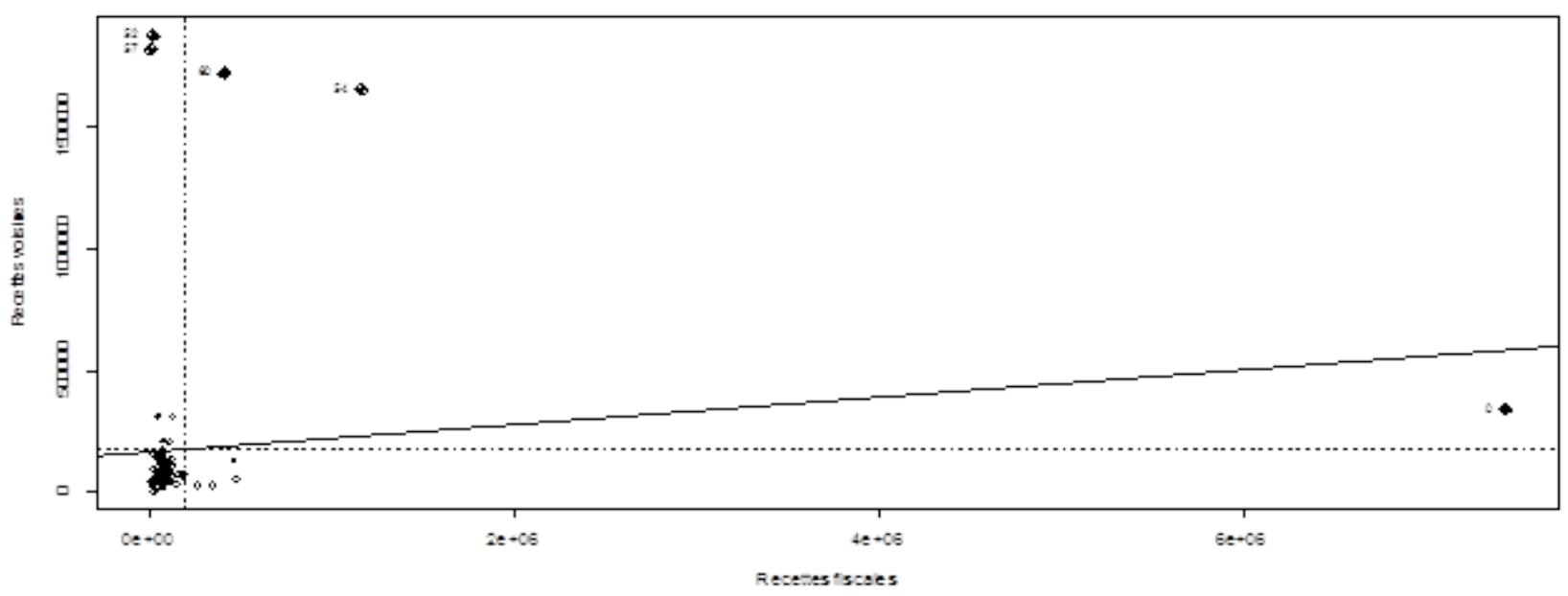

Graph 4. Diagram Moran on tax revenues

Source: Author's Work, 2016

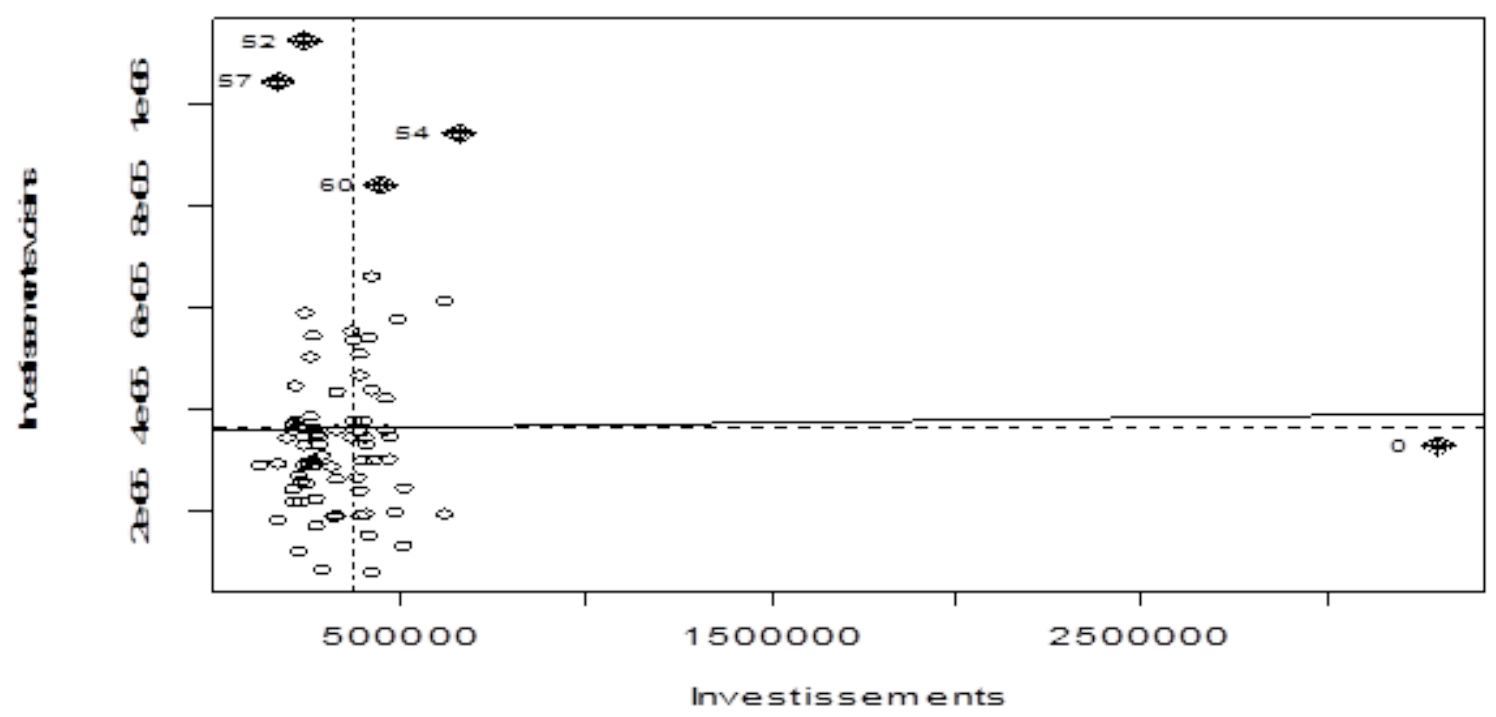

Graph 5. Diagram Moran on Investments

Source: Author's Works, 2016 


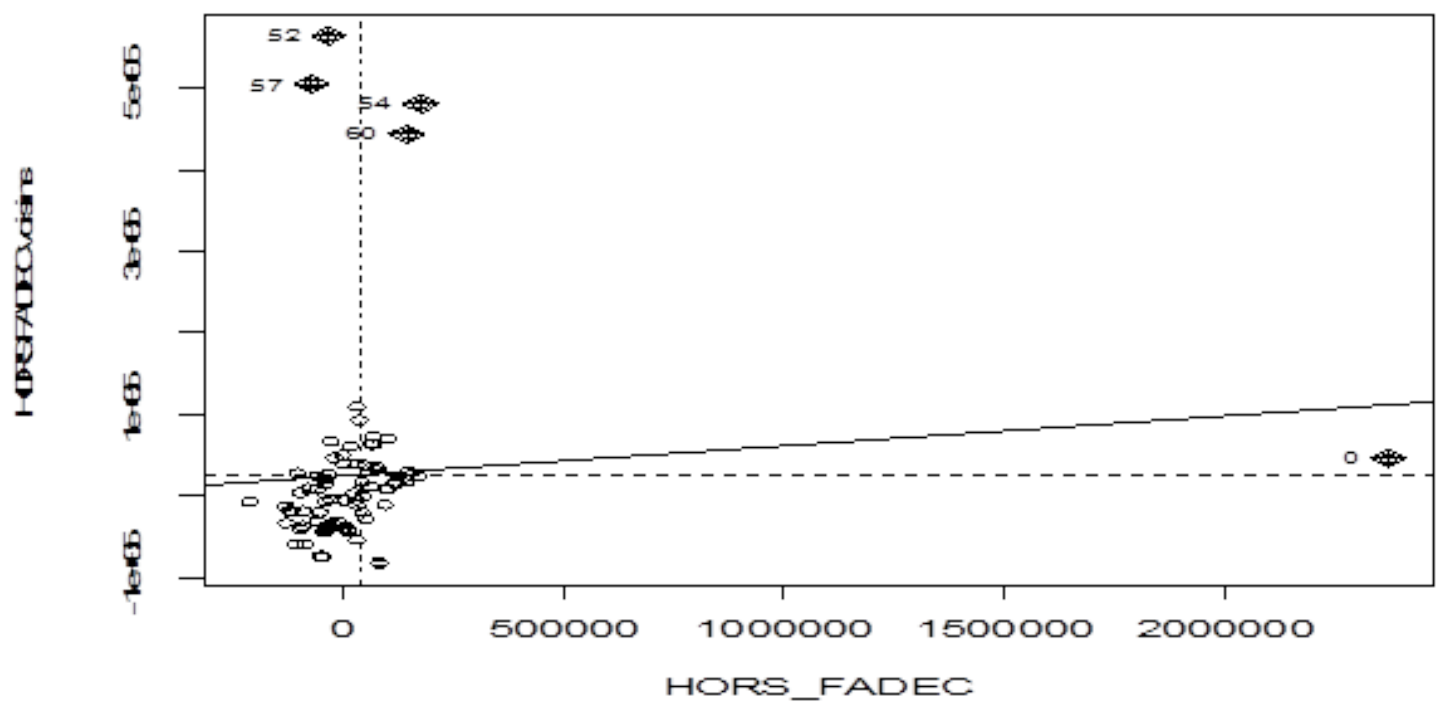

Graph 6. Moran diagram on Investment OUT FADEC

However, the critical probability (p-value) is less than $5 \%$ or $1 \%$ for non-tax revenues. It follows therefore that the non-tax revenues of the Municipalities of the Republic of Benin are significantly spatially correlated self. More $\mathrm{I}=0.2646$ is greater than zero, indicates a positive spatial autocorrelation.

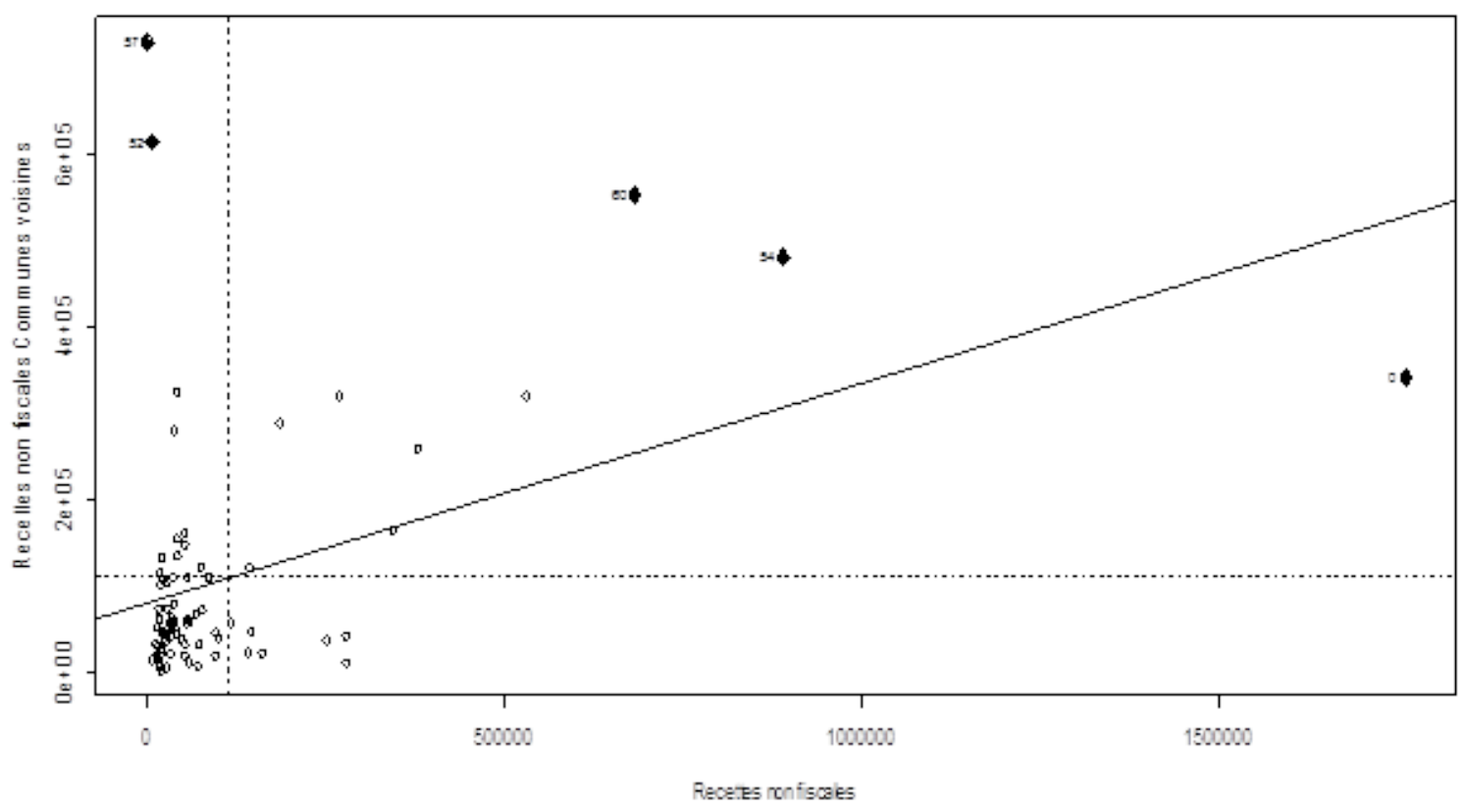

Graph 7. Moran diagram on non-tax revenues

Source: Author's Works, 2016 
3.7 Test Autocorrelation Global Geary on Tax Revenue, Income non Fiscal and Investment Expenditures (Type Contiguity)

Given the results of the test Moran, who conclude that non tax are self spatial correlation and that tax revenues and capital expenditures are not, it is important to test the overall autocorrelation using the Geary coefficient.

The results of this test are as follows:

Table 9. Geary test on different variables

\begin{tabular}{|l|l|l|l|l|l|}
\hline variables & G & E (G) & $\begin{array}{l}\text { Std. Err. } \\
(G)\end{array}$ & p-value & Obs. \\
\hline Tax revenue & $\mathbf{0 . 8 0 2 1 7 4 4 2}$ & $\mathbf{1 . 0 0 0 0 0 0 0 0}$ & 2094 & $\mathbf{0 . 0 3 6 2 6}$ & 77 \\
\hline $\begin{array}{l}\text { Non-tax } \\
\text { revenue }\end{array}$ & $\mathbf{0 . 6 4 6 6 0 6 9 7}$ & $\mathbf{1 . 0 0 0 0 0 0 0 0}$ & 3.7408 & $\mathbf{0 . 0 0 0 1 8 3 5}$ & 77 \\
\hline $\begin{array}{l}\text { investments } \\
\text { Investments } \\
\text { excluding } \\
\text { FADEC }\end{array}$ & $\mathbf{0 . 8 3 0 5 6 6 8 1}$ & $\mathbf{1 . 0 0 0 0 0 0 0 0}$ & 1.7935 & $\mathbf{0 . 0 7 2 8 9}$ & 77 \\
\hline
\end{tabular}

Source: Author's Works, 2016

The results reveal that Geary threshold of $10 \%$, there is a spatial autocorrelation are values of different variables. Indeed, for these variables, the critical probability (p_value) is less than $10 \%$ which leads to a rejection of the null hypothesis that postulates an absence of spatial autocorrelation. Furthermore, the value of the coefficient is less than 1 for all three variables, it follows that the spatial autocorrelation detected through the critical probability is positive.

On the threshold of $1 \%$ by cons, only the non-tax revenues are spatially auto correlated significantly.

It is however important to note that in the literature, Moran is often preferred to Geary due to greater overall stability (Upton and Fingleton, 1985). It therefore follows that the conclusion of lack of spatial autocorrelation in tax revenues and investment spending and the presence of spatial autocorrelation of nontax revenue that Moran tests resulted is more likely. According to these results, the values of income tax, capital expenditure and investments adjusted for transfers FADEC are randomly distributed on the national territory while non-tax revenues are self-spatial correlation. 


\subsection{Determination of Common Neighborhood Strong Interaction Space}

\section{Moran test on local tax revenue and out investments FADEC}

Following the global spatial autocorrelation tests, it is important to ascertain the existence of local autocorrelation. In other words, it is to check whether despite no overall correlation, there is not the Municipalities of the Republic of Benin, the levels of tax revenues and investments influence each other in because of neighborhood ties that exist between them.

The results of the test of the appreciation of the local spatial association on tax revenues indicates on the 77 communes of Benin, only the municipalities of Cotonou, Abomey and Sèmè-Kpodji have a neighborhood that focuses level tax revenue greater than the overall average. Indeed, the value of the P-value for the local Moran index is less at $5 \%$ for each of the three municipalities. These results confirm the observations made empirically in these three municipalities. Indeed, a municipality of Cotonou in its immediate neighborhood, the City of Abomey in 2013 which shows a level of revenue Tax 1158522000 FCFA. Reciprocally, the Commune of Abomey has in its immediate vicinity the Cotonou Town which in 2013 posted a level of tax revenue 7439154000 FCFA.

The same results are obtained with local Moran test on investments outside FADEC. Indeed of the 77 municipalities, only the municipalities of Cotonou, Abomey and Sèmè-Kpodji display critical probabilities below the $5 \%$ significance level. These municipalities thus have a neighborhood that concentrates an investment level off FADEC higher than the overall average.

\subsection{Moran of Local Test on Non-Tax Revenue}

As regards non-tax revenue, the results of the local Moran test reveal that the municipalities of Cotonou, Ouidah, Abomey, Porto-Novo, Sèmè-Kpodji and Adjarra have a neighborhood that concentrates a level of non-tax revenue than The general average. Indeed, the value of the P-value for the index of local Moran is less than 5\% for each of these municipalities. So, $i$ nteraction between Commons affect their respective levels of non-tax revenues.

This spatial correlation of non-tax revenues could come from the composition of these recipes that designate own municipal revenues that come from the products of services, domain and various sales. This is the set of items recorded in account 70 "Products of various domain services and sales”of the budget nomenclature.

The resource elements that produce non-tax revenues in public are quite varied and are sometimes operating revenues (close enough to the materials of the TDL), sometimes of services (Products shipments of administrative acts, acts of Civil Status and conventions, signatures of legalization... rights to market services, fees for parking and parking), sometimes products Heritage (quarry exploitation and mining in the town, burials products and concessions...). These are mainly related to the level and the urban structure of the common resources, resources of the subsoil, its geographical position, to brief its natural and cyclical economic data. 


\subsection{Econometric Analysis Space}

The spatial econometric analysis is needed to validate the robustness of the results of the exploratory analysis of spatial effects on the amounts of tax revenue, non-tax revenues and capital expenditures out FADEC. Spatial autocorrelation having been detected in non-tax revenues in order to check the strength exploratory results will be compared in the context of the present study, two econometric models of non-tax revenues: a model of ordinary linear regression and spatial econometric model. The spatial econometric model is an econometric model in which a space consideration is integrated.

In this part, we will proceed with an econometric analysis of non-tax revenues. The objective of this study is not to exhaustively search the determinants of non-tax revenues, we will only a few variables available in our database (see appendices).

The dependent variable will be made up of non-tax revenues. Regarding the explanatory variables, we will retain the size of the municipal population, urbanization rate, adult literacy rate of 15 or over and the proportion of the working population aged 15-64 engaged in the primary sector. These variables are close to the explanatory variables used in most empirical studies on the determinants of tax revenue. We then assume that the non-tax revenue could be explained by these variables because the variables have taken different combinations in the literature, often chosen based on data availability. An important element in the literature, it is the share of agriculture in GDP, which has often been perceived as having a negative effect although not significant in some studies. For example Shin (1969) and Piancastelli (2001) found that the share of agriculture in GDP has a negative and significant effect on the total share of tax revenues in GDP while ALM Martinez and Vazquez (2003) found a negative but insignificant effect of the share of agriculture in GDP, in a panel of developed and developing countries. As part of this study, given the lack of data on municipal GDP, the proportion of employed in the primary sector was used as a variable close to the share of agriculture in GDP. The urbanization rate which is calculated as the proportion ofCommune inhabitants living in urban areas and the literacy rate are explanatory variables that are assumed to have positive effects on the level of tax and nontax revenue. Regarding the literacy rate, studies have shown that people are more likely to know the reasons for the payment of taxes and other charges in a more educated society than in a less educated society and this has a positive effect on tax compliance (tax effort of ECOWAS countries, WAMA 2011). According to the same study, the coefficient associated with the urbanization rate is expected to be positive as demand for public services increases with the increase of urban population and many public sector activities are concentrated in cities.literacy are explanatory variables that are assumed to have positive effects on the level of tax and nontax revenue. Regarding the literacy rate, studies have shown that people are more likely to know the reasons for the payment of taxes and other charges in a more educated society than in a less educated society and this has a positive effect on tax compliance (tax effort of ECOWAS countries, WAMA 2011). According to the same study, the coefficient associated with the urbanization rate is expected to be positive as demand for public services increases with the increase of urban 
population and many public sector activities are concentrated in cities.literacy are explanatory variables that are assumed to have positive effects on the level of tax and nontax revenue. Regarding the literacy rate, studies have shown that people are more likely to know the reasons for the payment of taxes and other charges in a more educated society than in a less educated society and this has a positive effect on tax compliance (tax effort of ECOWAS countries, WAMA 2011). According to the same study, the coefficient associated with the urbanization rate is expected to be positive as demand for public services increases with the increase of urban population and many public sector activities are concentrated in cities.

The aim is to verify the robustness of the findings of the exploratory analysis, we consider successively the Ordinary Least Square and SAR model.

The estimation results are summarized in the following table:

Table 10. Summary of econometric analysis

\begin{tabular}{|c|c|c|c|c|c|c|}
\hline \multirow{2}{*}{$\begin{array}{l}\text { Non-tax } \\
\text { revenues }\end{array}$} & \multicolumn{2}{|l|}{ coefficients } & \multicolumn{2}{|c|}{ RobustStd. Err. } & \multicolumn{2}{|l|}{ p-value } \\
\hline & MCO & SAR & MCO & SAR & MCO & SAR \\
\hline $\begin{array}{l}\text { Total } \\
\text { population }\end{array}$ & 1624 & $\begin{array}{l}1.5757 \mathrm{e}+ \\
00\end{array}$ & 0141 & $1.3914 \mathrm{e}-01$ & $\begin{array}{l}<2 \mathrm{e}-16 \\
* * *\end{array}$ & $<2 \mathrm{e}-16$ \\
\hline $\begin{array}{l}\text { Urbanization } \\
\text { rate }\end{array}$ & 1218.198 & $\begin{array}{l}1.3966 \mathrm{e}+ \\
03\end{array}$ & 741905 & $\begin{array}{l}7.1920 \mathrm{e}+ \\
02\end{array}$ & 0.1050 & 0.05216 \\
\hline Literacy rate & 1474.873 & $\begin{array}{l}1.9342 \mathrm{e}+ \\
03\end{array}$ & 1507.020 & $\begin{array}{l}1.4762 \mathrm{e}+ \\
03\end{array}$ & 0.3310 & 0.19012 \\
\hline $\begin{array}{l}\text { Proportion of } \\
\text { the active } \\
\text { population in } \\
\text { the primary } \\
\text { sector }\end{array}$ & -1681.117 & $\begin{array}{l}-1.0866 e+ \\
03\end{array}$ & 825887 & $\begin{array}{l}9.0088 \mathrm{e}+ \\
02\end{array}$ & $\begin{array}{l}\mathbf{0 . 0 4 5 5} \\
*\end{array}$ & 0.22777 \\
\hline Constant & $-98132,054$ & $\begin{array}{l}-1.6371 e+ \\
05\end{array}$ & 98535.580 & $\begin{array}{l}1.0562 e+ \\
05\end{array}$ & 0.3226 & 0.12113 \\
\hline Rho & & 0.13152 & & & & 0.17882 \\
\hline R-squared & 0.8093 & & & & & \\
\hline
\end{tabular}




\section{Codes of levels of meaning '.' 0 '***' 0.001 '**' 0.01 '*' 0.050 .1 " 1}

Source: Works of the author, 2016

\section{Discussion}

\subsection{Results of the Model Mco}

The determination coefficient being 0, 8093 and given the fact that the critical probability variable population FADEC and Proportion occupied in the primary sector is less than the $\alpha$ limit $=5 \%$, the coefficients of these variables were significantly different from zero. As for the rate of urbanization and literacy, critical probabilities are higher than 0.05 the coefficients of these variables are not significantly different from zero.

Comparing these results with those of the SAR model is indispensable given the presence of autocorrelation revealed by exploratory analysis. Indeed, in the presence of spatial autocorrelation, the results of the SAR model should be better than those of the OLS model.

\subsubsection{Results Sar Model}

Critics probability and estimated parameters are the best in the SAR model for the urbanization rate and the literacy rate. The critical probability of the population is the same in both models. The "rho"which represents the impact of non-tax revenues neighboring municipalities on a given joint, is however not significant at the minimum threshold of $5 \%$ with a value close to $0.1(0.1788)$.

It should be noted that the estimated parameter of the urbanization rate is significantly different from zero in any of the two models.

\subsection{Verification Assumptions}

Based on the results of exploratory and econometric analyzes, hypothesis testing can be summarized as follows:

Table 11. Checking assumptions

\begin{tabular}{|l|l|}
\hline HYPOTHESES & DECISION \\
\hline spatial autocorrelationtax revenues & rejected e \\
\hline spatial autocorrelation non-tax revenues & accepted \\
\hline $\begin{array}{l}\text { Spatial autocorrelation of investment } \\
\text { spending outside FADEC }\end{array}$ & rejected \\
\hline Significant contribution rate of urbanization & rejected \\
\hline
\end{tabular}


non-tax revenue

\section{Source: Author}

Thus, the first hypothesis is checked only for non-tax revenues. Indeed, the test for assessing the overall autocorrelation performed by the Moran index led to the non-rejection of the null hypothesis of no spatial autocorrelation tax revenues and investment spending. As regards non-tax revenue, these tests were conclusive.

The results of the spatial econometric model disprove the second hypothesis that the rate of urbanization contributes significativily amounts of non-tax revenues of Commons. Calculating the correlation matrix show also a weak linear dependence between the rate of urbanization and the level of revenue non tax (linear correlation coefficient $=0,58$ ) and secondly between the urbanization and expenses investment off FADEC (linear correlation coefficient $=0.35$ ).

\section{Conclusion}

In this study we conducted an empirical analysis of the spatial distribution of $r$ tax evenue, non-tax revenues and capital expenditure of all Municipalities of the Republic of Benin. With Moran indicators (global and local), we detected a lack of spatial dependence between levels of income tax and Public investment spending. The analyzes, however, revealed a spatial autocorrelation of non-tax revenues of Commons. So, It appears that there is no spatial autocorrelation between tax revenues and investments of Commons in Benin Republic. This also means that the distribution of tax revenue and capital expenditure of Commons on the Beninese territory is random. Local indicators have revealed that there are municipalities that concentrate in their neighborhood, levels of non-tax revenue above average and consequently influence the overall situation of Commons. These are the municipalities of Cotonou, Abomey, Ouidah, Sèmè-Kpodji, Porto-Novo and Adjarra. Indicators also that despite the absence of global autocorrelation there is a concentration of income tax and expenditure Investment in the municipality of Cotonou and Abomey calavi and Sèmè-Kpodji.

\section{Referneces}

Amemiya T. (1985). Advanced Econometrics. Harvard University Press.

Anselin L. (1980). Estimation Methods for Spatial Autoregressive structures. Cornell University Regional Science Essay and Monograph Series \# 8 Ithaca, NY.

Anselin L. (1988a). Spatial Econometrics: Methods and Models, Kluwer Academic Publishers.

A nselin L. (1988b). Lagrange Multiplier Test Diagnostics for Spatial Dependence and Spatial Heterogeneity. Geographical Analysis, 20, 1-17.

Anselin L. (2000). Spatial Econometrics. In Baltagi B. (Ed.), Companion to Econometric s, 
Basil Blackwell.

Anselin \& Bera, A. K. L. (1998). Spatial Dependence in Linear Regression Modelswith year Application to Spatial Econometrics. In Ullah A. Giles \& DEA (Eds.), Handbook of Applied Economics Statistics, Springer-Verlag, 21-74.

Anselin, L., Bera, A. K., Florax, R., \& Yoon, J. (1996). Simple Diagnostic Tests for Spatial Dependence. Regional Science and Urban Economics, 26, 77-104.

Anselin, L., \& Kelejian H. (1997). Testing for Spatial Error Autocorrelation in thepresence of Endogenous regressor s. International Regional Science Review, 20, 153-182.

Anselin \& Rey, S. L. (1991). Properties of Tests for Spatial Dependence in Linear Regression Models. Geographical Analysis, 23, 112-131.

Anselin, L., \& Smirnov, O. (1996). Efficient Algorithms for Constructing Proper Higher Order Spatial Lag Operators. Journal of Regional Science, 36, 67-89.

Anselin, L., Varga, A., \& Acs, Z. (1997). Local Geographic Spillovers entre University Research and High Technology Innovations. Journal of Urban Economics, 42, 422-448.

Arbia G. (1989). Spatial Data Configuration in Statistical Analysis of Regional Economic and Related Problems, Kluwer Academic Publishers.

Aten, B. (1997). Does Space Matter? International Compa risons of the Prices of Tradables and Nontradables. International Regional Science Review, 20, 35-52.

Bera \& Yoon, A. K. M. (1993). Testing Specification with Locally Misspecified Alternative, Econometric Theory, 9, 649-658.

Can, A. (1992). Specification and Estimation of Housing Hedonic Price Models. Regional Science and Urban Economics, 22, 453-474.

Can Megboluge, A. I. (1997). Spatial Dependence and House Price Index Construction. Journal of Real Estate Finance ndEconomics, 14, 203-222.

Case, A. (1991). Spatial Patterns in Household Demand. Econometrica, 59, 953-965.

Case, A C., Rosen, Hines. H. S., \& J. R. (1993). Spillovers Budget and Fiscal PolicyInterdependence: Evidence from the States. J journal of Public Economics, 52, 285-307.

Chou, Y. H. (1991). Map Resolution and Spatial Autocorrelation. Geographical Analysis, 23, 228-228-246.

Cliff, A. D., \& Ord, J. K. (1973). Spatial Autocorrelation Pawn.

Cliff, A. D., \& Ord, J. K. (1981). Spatial Processes: Models and Applications, Pion.

Cressie, N. (1993). Statistics for Spatial Data, John Wiley. 
Dubin, R. A. (1998). Spatial Autocorrelation: A Primer. Journal of Housing Economics, 7, 304-327.

Dubin, R. Pace, R. K., \&Thibodeau, T. G. (1999). Spatial autoregression Techniques for Real Estate Data. Journal of Real Estate Techniques, 7, 79-95.

Griffith, D. A. (1992). What is Spatial Autocorrelation? Reflections on the Past 25 yearsof Spatial Statistics. The Geographical Area, 21, 265-280.

Heijmans, H. D. R., \& Magnus, J. R. (1986a). Asymptotic Normality of Maximum Likelihood Estimators Obtained from goal Normally Distributed Dependent Observation. Econometric Theory, 12, 374-412.

Heijmans, H. D. R., \& Magnus, J. R. (1986b). Consistent Maximum-likelihood estimation with Dependent Observations: The General (non-normal) Case and the Normal Case. Journal of Econometrics, 32, 253-285.

Kelejian, H. H. D. P., \& Robinson (1992). Spatial Autocorrelation: A New Compu tationally Simple Test with an Application to per Capita Country Police Expenditures. Regional Science and Urban Economics, 22, 317-331.

Kelejian, H. H. D. P., \& Robinson (1993). A Suggested Method of Estimation for Spatial Models Interdependent with Autocorrelated Errors, and an Application to a Country Country Police Expenditure Expenditure. Papers in Regional Science, 72, 297-312.

Macedo, A. C. B. (1998). Hedonic Price Models with Spatial Effects: An Application to the Housing Market of Belo Horizonte, Brazil. RevistaBrasileira de Economia, 52, 63-81.

Moran P. (1948). The Interpretation of Statistical Maps. Journal of the Royal Statistical Society, 10B, 243-251.

Moran, P. (1950a). Notes on Continuous Stochastic Ph enomena. Biometrika, 37, 17-23.

Moran, P. (1950b). A Test for Serial Independence of Residuals. Biometrika, 37, 178-181.

Ord, K. (1975). Methods for Estimation of Spatial Interaction models. Journal of the American Statistical Associa tion, 70, 120-126.

Pace, R. K., \& Gilley, O. W. (1997). Using the Spatial Configuration of the Data to Improve Estimation. Journal of Real Estate Finance and Economics, 14, 33 3-340.

Student (1914). The Elimination of Spurious Correlation due to position in Time Space gold. Biometrika, 5, 351-360.

Tiefelsdorf, M. (2000). Spatial Modeling Processes, Lecture Notes in Eart h Sciences, No. 87, Springer.

- $\quad$ Figures in Benin of Commons (2003-2010). 
- The numbers in the Commons Benin (201 1-2013).

- $\quad$ Papers villages and urban neighborhoods, RGPH 4.

\section{Copyright}

Copyright for this article is retained by the author(s), with first publication rights granted to the journal.

This is an open-access article distributed under the terms and conditions of the Creative Commons Attribution license (http://creativecommons.org/licenses/by/4.0/). 